\title{
HCV Infection and B-Cell Lymphomagenesis
}

\author{
Masahiko Ito, ${ }^{1,2}$ Hideki Kusunoki, ${ }^{1}$ Keiko Mochida, ${ }^{3}$ \\ Kazunari Yamaguchi, ${ }^{1}$ and Toshiaki Mizuochi ${ }^{1}$ \\ ${ }^{1}$ Department of Research on Blood and Biological Products, National Institute of Infectious Diseases, 4-7-1 Gakuen, \\ MusashiMurayama-shi, Tokyo 208-0011, Japan \\ ${ }^{2}$ Department of Infectious Diseases, Hamamatsu University School of Medicine, 1-20-1 Handayama, Higashi-ku, \\ Hamamatsu 431-3192, Japan \\ ${ }^{3}$ Department of Bacterial Pathogenesis and Infection, National Institute of Infectious Diseases, 4-7-1 Gakuen, \\ MusashiMurayama-shi, Tokyo 208-0011, Japan
}

Correspondence should be addressed to Toshiaki Mizuochi, miz@nih.go.jp

Received 7 March 2011; Revised 14 June 2011; Accepted 17 June 2011

Academic Editor: Daniele Vallisa

Copyright ( $) 2011$ Masahiko Ito et al. This is an open access article distributed under the Creative Commons Attribution License, which permits unrestricted use, distribution, and reproduction in any medium, provided the original work is properly cited.

\begin{abstract}
Hepatitis $\mathrm{C}$ virus (HCV) has been recognized as a major cause of chronic liver diseases worldwide. It has been suggested that $\mathrm{HCV}$ infects not only hepatocytes but also mononuclear lymphocytes including B cells that express the CD81 molecule, a putative $\mathrm{HCV}$ receptor. HCV infection of B cells is the likely cause of B-cell dysregulation disorders such as mixed cryoglobulinemia, rheumatoid factor production, and B-cell lymphoproliferative disorders that may evolve into non-Hodgkin's lymphoma (NHL). Epidemiological data indicate an association between HCV chronic infection and the occurrence of B-cell NHL, suggesting that chronic HCV infection is associated at least in part with B-cell lymphomagenesis. In this paper, we aim to provide an overview of recent literature, including our own, to elucidate a possible role of $\mathrm{HCV}$ chronic infection in B-cell lymphomagenesis.
\end{abstract}

\section{Introduction}

Hepatitis $\mathrm{C}$ virus (HCV) is an enveloped positive-strand RNA virus that belongs to the Flaviviridae family [1]. HCV infection is a worldwide problem affecting nearly 200 million people [2] and causes prolonged and persistent diseases in virus carriers, often leading to chronic hepatitis, cirrhosis, and hepatocellular carcinoma [3]. Although the liver is considered to be the primary target of HCV infection, extrahepatic manifestations, such as mixed cryoglobulinemia, which is a systemic immune complex-mediated disorder characterized by B-cell proliferation that may evolve into overt B-cell non-Hodgkin's lymphoma (B-NHL), are often recognized among patients persistently infected with $\mathrm{HCV}$ $[4,5]$. In fact, epidemiological evidence strongly suggests a close link between chronic HCV infection and B-NHL $[6,7]$. The pathogenic role of HCV in B-cell disorders has been suggested in reports wherein a clinical resolution of the Bcell dysfunctions, stated above, was observed after successful anti-HCV treatment using interferon (IFN) [8-10]. Based on such evidences, a possible role of $\mathrm{B}$ cells in $\mathrm{HCV}$ pathogenesis has been postulated but not yet conclusively demonstrated.
The objective of this paper is to summarize recent literature focused on the possible involvement of HCV infection in B-cell lymphomagenesis, which could offer new insights into the role of B cells in the pathogenesis of $\mathrm{HCV}$ infection.

\section{Does HCV Infect and Replicate in Peripheral B Cells of Chronic Hepatitis C (CHC) Patients?}

$\mathrm{HCV}$, as the name indicates, has been regarded as a hepatotropic virus. However, the possibility that HCV infects cells other than hepatocytes cannot be excluded. In the early 1990s, the existence of HCV RNA was demonstrated by PCR in not only serum/plasma [11] and liver tissues [12] but also in peripheral blood mononuclear cells (PBMCs) of patients infected with HCV $[13,14]$. Muller et al. first reported in 1993 that HCV RNA could be found in B cells [15]. They predicted that PBMC, particularly B cells, could be sites for HCV replication and may serve as reservoirs of HCV infection. Moldvay et al. demonstrated that negative-strand HCV RNA, a replicative intermediate of $\mathrm{HCV}$, was observed in PBMC of 
patients with CHC (6 of 11) by in situ hybridization [16]. Muratori et al. reported negative-strand HCV RNA within PBMC detected by fluorescein-tagged in situ RT-PCR (12 of 14 patients with $\mathrm{CHC}$ ) [17]. Further evidence suggested that HCV replicates in B cells. For example, Morsia et al. demonstrated the replication of $\mathrm{HCV}$ in $\mathrm{CD} 19^{+} \mathrm{B}$ cells by detecting the negative-strand RNA although their sample size was very small (1 of 3 patients with $\mathrm{CHC}$ was positive) [18]. Around the same time, Pileri et al. demonstrated that the HCV envelope protein E2 binds the CD81 molecule that is expressed on not only hepatocytes but also various cell types including B cells [19]. This finding thus provided a rationale for the notion that HCV infects and replicates in B cells. Several years later, Gong et al. confirmed the existence of negative-strand HCV RNA in PBMC of patients with CHC (14 of 35) [20]. Some argued that the negative-strand HCV RNA in PBMC may be due to mere contamination or passive absorption by circulating HCV in peripheral blood. They successfully excluded this possibility by demonstrating the expression of HCV-encoding protein, NS5, which indicates that $\mathrm{HCV}$ not only replicates but also produces $\mathrm{HCV}$ protein in PBMC. Their results are in agreement with an earlier study by Sansonno et al. in which HCV core and NS3 proteins were detected in PMBC of patients with CHC [21].

Occult HCV infection is characterized by the presence of HCV RNA in the liver and the absence of both HCV RNA and anti-HCV antibodies in serum. Castillo et al. detected HCV RNA in PBMC of 40 of 57 (70\%) patients with occult HCV infection [22]. In a subsequent report, they confirmed the replication of HCV in PBMC of patients with occult HCV infection by detecting both positive and negative strands of HCV RNA using a strand-specific RT-PCR and in situ hybridization techniques [23]. Meanwhile, JanuszkiewiczLewandowska et al. demonstrated the presence of HCV RNA in PBMC of patients who underwent antiviral chemotherapy and therefore were HCV-serum negative [24]. Collectively, these findings not only favor the notion that PBMC, particularly B cells (discussed later), infected with $\mathrm{HCV}$ can serve as reservoirs for persistent $\mathrm{HCV}$ infection but are also an alert that PBMC of patients with $\mathrm{CHC}$, including patients with occult $\mathrm{CHC}$, could be potentially infectious even when HCV RNA is negative in their sera. There has been a debate over which cell population in PBMC is the main target for $\mathrm{HCV}$ infection. An array of evidence suggests that HCV replicates in various cell types of PBMC, including peripheral dendritic cells, monocytes, and macrophages [25-27]. A recent study by Kondo et al. demonstrated that lymphotropic HCV (SB strain) could infect not only established T-cell lines and B-cell lines but also primary naïve $\mathrm{CD} 4^{+} \mathrm{T}$ cells, suggesting that $\mathrm{HCV}$ replication in such $\mathrm{T}$ cells suppressed their proliferation and development in Th1 commitment [28]. Under these circumstances, a number of reports have indicated that HCV infects CD81-positive lymphocytes, preferentially B cells $[18,29-31]$. Our recent study also clearly demonstrated that HCV RNA and HCV core and NS3 proteins are detected in $\mathrm{CD} 19^{+}$but not in $\mathrm{CD} 19^{-}$ PBMC [32]. Furthermore, Inokuchi et al. confirmed that negative-strand HCV RNA, regarded as a marker of viral replication, was detected in B cells of patients with $\mathrm{CHC}$ [33].
Considering this evidence, it can be concluded that HCV infects and replicates in PBMC, particularly in the CD19+ $\mathrm{B}-$ cell subset, of patients with CHC. An intriguing question has emerged as to whether different HCV variants or B-tropic HCV cause HCV infection in the $\mathrm{CD} 19^{+} \mathrm{B}$ cells of patients with $\mathrm{CHC}$ or not. When cDNA sequences derived from RNA isolated from plasma and $\mathrm{CD} 19^{+} \mathrm{B}$ cells of randomly selected patients with $\mathrm{CHC}$ were compared, limited variations were found in the internal ribosome entry site (IRES) region (our unpublished data). However, as predicted by a computer program named mfold, these nucleotide substitutions did not affect RNA secondary structure or thermodynamic stability of IRES region [34]. Furthermore, the amino acid sequences in the hypervariable region 1 (HVR1), which directly reflect clonal variations of $\mathrm{HCV}$, did not show any distinct differences between plasma and $\mathrm{CD} 19^{+} \mathrm{B}$ cells of patients with $\mathrm{CHC}$. These results indicate that $\mathrm{HCV}$ RNA isolated from CHC B cells is indistinguishable from RNA isolated from plasma of the same patient with $\mathrm{CHC}$ (our unpublished data). Sequence polymorphisms located at IRES and HVR1 of E2 were observed in lymphoid cells of individuals with persistent HCV infection, strongly favoring the concept of HCV lymphotropism. Recently, HCV variants observed in B cells showed poor translational activity in hepatocytes but not in B-cell lines, indicating that adaptive mutations had occurred in B cells [35]. However, our results do not support the concept of lymphotropism or B-tropism of HCV in patients with CHC [30] but instead are in good agreement with studies by Muller et al. in which the PCR products obtained from serum and PBMC specimens of an $\mathrm{HCV}$-positive individual were found to have nearly identical sequences [15]. Although the number of clones analyzed was limited, our conclusion that HCV RNA isolated from $\mathrm{CD} 19^{+} \mathrm{B}$ cells is indistinguishable from RNA isolated from the plasma of the same patient with $\mathrm{CHC}$ is inconsistent with the concept of B-tropic HCV RNA. Further investigation involving a large number of $\mathrm{HCV}$ patients would be necessary to support this conclusion.

Overall, the data accumulated to date strongly suggest that HCV infects and replicates in the peripheral B cells of patients with $\mathrm{CHC}$. However, currently it is not known whether a novel HCV strain, B-tropic HCV RNA, preferentially infects peripheral B cells or not. The role of B cells in the pathogenesis of HCV infection is examined in the next section.

\section{Peripheral B Cells May Serve as Reservoirs for Persistent Infection of HCV}

As described in the previous section, evidence indicates that peripheral $\mathrm{B}$ cells in patients with $\mathrm{CHC}$ were infected with HCV and thus may serve as HCV reservoirs. This evidence posed a logical question as to how HCV evades the innate antiviral immune responses in B cells. However, this important issue has so far not been formally investigated.

Sensing mechanisms for invading viruses in host immune cells consist of toll-like-receptor (TLR-) mediated [36] as well as retinoic-acid-inducible-gene-I-(RIGI-) mediated [37] pathways. Both pathways culminate in 


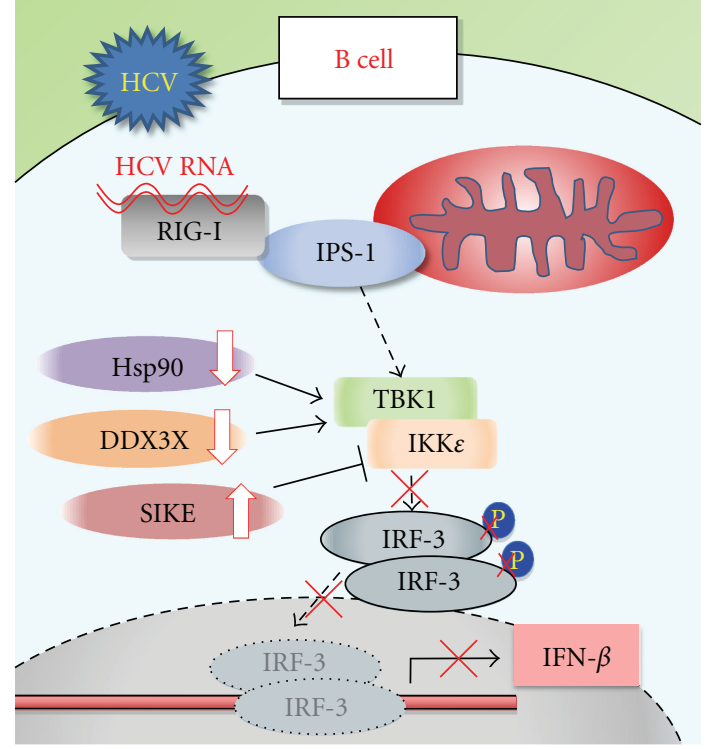

FIGURE 1: Impaired innate antiviral immunity in B cells of patients with chronic hepatitis $\mathrm{C}$.

the translocation of IFN regulatory factor-3 (IRF-3) to the nucleus to transcribe the IFN- $\beta$ gene. Type-I IFN, for example, IFN- $\beta$, plays a critical role in the innate antiviral immune response $[38,39]$. In our recent study, it was found that the expression levels of RIG-I and its adaptor molecule, IFN promoter-stimulator 1 (IPS-1), were substantially enhanced in $\mathrm{CHC}$ B cells. However, dimerization and the subsequent nuclear translocation of IRF-3 were almost undetectable in CHC B cells. It has been demonstrated that TANK-binding kinase-1 (TBK1) and $\mathrm{I} \kappa \mathrm{B}$ kinase- $\varepsilon$ (IKKE) are essential for the phosphorylation of IRF-3 [40]. The constitutive expression levels of both kinases were found to be markedly enhanced in CHC B cells. However, the reduced expression of TBK1 stabilizers, including Hsp90 [41] and DDX3X [42], and the enhanced expression of the IKK suppressor SIKE [43], were observed in CHC B cells, suggesting that IRF-3 phosphorylation was downregulated. Hence, transcription of the IFN- $\beta$ gene was not augmented. These results strongly suggest that HCV infection circumvents innate antiviral immune responses, that is, type I IFN production in B cells, and (Figure 1) thus, takes advantage of B cells for persistent infection.

It can be assumed that, among B-cell subsets, memory $B$ cells are the main reservoirs of HCV infection primarily because of their long lifespans. Supporting this notion, our recent study indicated that $\mathrm{CD} 19^{+} \mathrm{CD} 27^{+}$cells (memory $B$ cells [44]) are recruited to the liver of patients with CHC through the interaction between CXCR3 expressed on $\mathrm{CD} 19^{+} \mathrm{CD} 27^{+}$cells and IP-10 (IFN- $\gamma$-inducing protein $10 \mathrm{kD}$ ) produced in the liver [45]. This strategy would be beneficial for HCV in securing sites for long-lasting infection. HCV infection of hepatocytes has long been considered an a priori assumption. However, this assumption does not necessarily mean that hepatocytes are the exclusive target of $\mathrm{HCV}$ infection. HCV may search for reservoir sites in other cellular compartments if the liver becomes unsuitable for replication, perhaps due to cellular destruction caused by the host immune response and/or by the development of conditions such as cirrhosis and hepatocellular carcinoma.

Lymphoid reservoirs of HCV infection could play a role in viral persistence $[29,46-48]$. Several maneuvers are employed for persistent infection of HCV [49]. Viral modulation is an effective strategy to escape host immune responses [50]. Another strategy is the suppression of the innate immunity of host by viral components. These components include HCV E2 protein, which acts as a decoy target of protein kinase R (PKR) [51]; HCV NS3/4A protein, which cleaves the adaptor molecules TRIF and IPS-1 and thereby blocks TLR3 and RIG-I signaling, respectively [52, 53]; HCV NS5A protein, which inhibits IFN-stimulated genes expression [54] and PKR function [55]; HCV core protein, which interferes with JAK/STAT signaling $[56,57]$. Regardless of the mechanisms, the infection and replication of $\mathrm{HCV}$ in peripheral B cells should be considered barriers to the treatment of patients with $\mathrm{CHC}$ with antiviral regimens. Based on the notion that peripheral B cells serve as reservoirs for persistent HCV infection and from a therapeutic perspective, it may be beneficial to eliminate peripheral $\mathrm{B}$ cells in patients with $\mathrm{CHC}$ by the administration of anti-Bcell antibodies, such as rituximab, along with combination therapy with peginterferon and ribavirin to eliminate circulating HCV in the blood, leading to a synergistic effect on HCV clearance in patients with CHC.

\section{HCV Infection and B-Cell Lymphomagenesis}

The striking association between HCV infection and type II mixed cryoglobulinemia (MC) has been well documented $[4,58,59]$. MC is a benign lymphoproliferative disorder and is regarded as a variant of low-grade B-NHL. Therefore, lymphotropism of HCV suggests that HCV could play a pathogenic role in the clonal proliferation of $B$ cells $[60,61]$. Because HCV RNA genomic sequences are not able to integrate into the host genome, indirect mechanisms of malignant transformation should be considered. In this regard, the persistent stimulation of $B$ cells by viral antigens and/or the enhanced expression of lymphomagenesis-related genes could be responsible for leading to polyclonal and later to monoclonal expansion of B cells. Furthermore, the occurrence of a subsequent transformation may lead to B-NHL.

A number of epidemiological studies regarding the association between HCV infection and the occurrence of B-NHL have been carried out [5, 7, 62-65]. A substantial geographic as well as demographic variation exists in the association between HCV infection and risk of B-NHL. A positive association was found in Italy, Japan, and USA. A recent case-control study with a large number of subjects from the International Lymphoma Epidemiology Consortium based in Europe, North America, and Australia further confirmed the association between HCV infection and NHL and specific B-NHL subtypes, that is, diffuse large B-cell lymphoma (DLBCL), marginal zone lymphoma, and lymphoplasmacytic lymphoma [6]. In contrast, other studies from Northern Europe, UK, and Canada failed to show the 
association. Geographic differences in HCV genotype have been thought to cause these discrepancies [66] although this remains controversial. Large-scale, population-based, wellcontrolled studies are necessary to reach a robust conclusion. It can be concluded that, at least in areas with a high prevalence of HCV carriage, HCV is an important risk factor for B-cell lymphomagenesis.

In this paper, we propose a novel hypothesis that peripheral B cells serve as reservoirs for persistent HCV infection. We also suggest that long-lasting HCV infection in B cells may induce lymphoproliferative disorders that may eventually evolve into B-cell NHL, although little is known about the mechanism responsible for B-cell lymphomagenesis. In the remainder of this section, the possible mechanisms of B-NHL tumorigenesis induced by $\mathrm{HCV}$ infection will be discussed based on current knowledge of lymphomagenesisrelated genes.

Activation-induced cytidine deaminase (AID) is essential for somatic hypermutation (SHM) and class switch recombination of immunoglobulin genes in B cells [67-69]. Recently, it has been proposed that AID may be instrumental in the initiation and progression of B-NHL. This is because a malfunction in either of the two processes stated above is apparently responsible for chromosomal translocations and aberrant SHM, which are the two main causes of genetic lesions associated with B-NHL [70, 71]. Several oncogenes have been demonstrated to be targets for SHM with immunoglobulin genes. In many cases, these anomalies activate the DNA damage response system that either allows DNA repair or eliminates the aberrant B-cell clones [72]. Failure of these repair systems may be a cause of B-cell malignancies. Specific features of SHM are the predominance of single-based substitution, the preference for transitions over transversion, and the specific targeting of the RGYW/WRCY motif. Pasqualucci et al. showed that hypermutation of proto-oncogenes exists in DLBCL [71]. However, in HCVassociated NHL, the number of mutations in some protooncogenes was lower than that already found in HCVnegative B-cell NHL patients [73]. Because there is a close association between HCV infection and the incidence of BNHL, as described above [6,7], analyzing the expression levels of AID in CHC B cells is of great interest.

Lai et al. established a B-cell line (SB) from HCV-infected B-NHL cells. The virus particles produced from SB cell culture could infect primary human hepatocytes, Raji cells, and PBMC in vitro [74]. They examined the expression of AID in Raji cells and PBMC after HCV infection in vitro. It was found that HCV infection activated the expression of AID in Raji cells. AID expression level was also higher in PBMC of patients infected with HCV than in uninfected individuals [75]. However, their study did not assess which cell population showed an enhancement of AID expression. It was observed in our recent study that expression levels of AID mRNA were markedly enhanced in the $\mathrm{CD} 19^{+}$, but not in the CD19- ${ }^{-}$subset of patients with $\mathrm{CHC}$ [32]. Furthermore, the enhanced expression of AID protein was detected in the $\mathrm{CD} 19^{+} \mathrm{B}$-cell subset of patients with $\mathrm{CHC}$ [32]. The fact that this enhancement of AID expression is confined to the B-cell subset is extremely intriguing because several reports have demonstrated the augmented expression of AID in B-NHL $[26,76,77]$.

Using an AID-deficient mouse model, Pasqualucci et al. concluded that AID is required for germinal center-derived lymphomagenesis [78]. They addressed the issue of errors in AID-mediated antigen receptor gene modification processes being the principal contributors to the pathogenesis of human B-NHL. Increasing epidemiological evidence has highlighted the close correlation between HCV infection and B-NHL $[6,7,79]$. Thus, it is tempting to hypothesize that the enhancement of AID in CHC B cells is at least partly responsible for the initiation of lymphomagenesis. In fact, several recent studies suggest that AID is deeply involved in tumorigenesis [80-84]. Notably, HCV enhanced AID expression by NF- $\kappa \mathrm{B}$ activation through the expression of viral core proteins. Furthermore, NF- $\kappa \mathrm{B}$ expression was upregulated and activated by HCV NS2 proteins in HepG2 cells [85]. These findings suggest that inappropriate expression of AID acts as a DNA mutator that enhances genetic susceptibility to mutagenesis [86].

Additionally, enhanced expression of other lymphomagenesis-related genes including cyclin D1, cyclin D2, BAL, STK15, and galectin-3 in CHC B cells is worth considering [32]. Overexpression of CCND1, which alters cell-cycle progression, is frequently observed in various tumors and may contribute to tumorigenesis [87, 88], whereas CCND2 is known to be expressed at constitutively high levels in B-NHL [89]. BAL is a novel risk-related gene in DLBCL, a typical B-NHL [90], while STK15 is a gene highly expressed in a histologically aggressive type of NHL [91]. Galectin-3 is an antiapoptotic protein, highly expressed in DLBCL [92]. Presumably, the enhanced expression of these genes in CHC B cells [32] may also correlate with B-cell lymphomagenesis.

Tumor necrosis factor alpha-induced protein 3, also called A20, was first identified in 1990 as a TNF-induced cytoplasmic protein with zinc finger motifs [93], which thereafter has been described as a key player in the negative regulation of inflammation by terminating $\mathrm{NF}-\kappa \mathrm{B}$ signaling [94-96]. Recently, A20 has gained much attention as a novel tumor suppressor $[97,98]$. Honma et al. first reported that A20 is frequently inactivated or even deleted in mantle cell lymphoma and DLBCL, and they raised the possibility that inactivation of A20 may be at least partly responsible for lymphomagenesis [99, 100]. Other investigators have subsequently supported their findings [101, 102]. Moreover, A20 also regulates antiviral signaling as well as programmed cell death [103-105]. Currently, the expression, biological activities, and mechanisms of action of A20 have been the focus of attention on a wide scale [106]. Interestingly, Ngueyn et al. reported [107] that the HCV core protein induced an increased expression of A20 in the human hepatocyte cell line HepG2, which has generated a genuine interest in the expression of A20 in peripheral B cells of patients with $\mathrm{CHC}$. Our preliminary data suggests that the A20 molecule is partially cleaved in CHC B cells (Kusunoki et al.; in preparation). An intriguing possibility is that the A20 gene interacts with and is mutated by AID, the expression of which is dramatically enhanced in $\mathrm{CHC} B$ cells [32]. In 


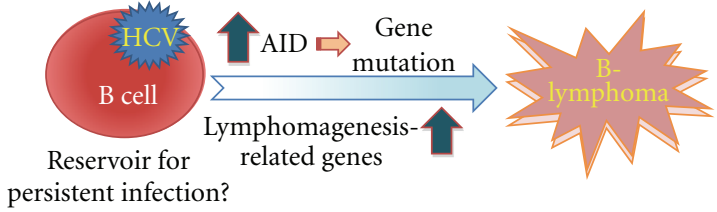

Figure 2: Role of HCV infection in B-cell lymphomagenesis, a hypothesis.

this regard, the expression levels of A20 in patients with B-NHL suffering from chronic HCV infection are worth investigating.

\section{Conclusion}

In this paper, we summarized recent studies illuminating the possible role of $\mathrm{HCV}$ infection in B-cell lymphomagenesis. We proposed a hypothesis that HCV utilizes B cells as reservoirs for persistent infection, which could result in the enhanced expression of lymphomagenesis-related genes, particularly AID, which is thought to be crucial for the initiation and progression of B-NHL (Figure 2). Elimination of HCV in plasma by antiviral reagents as well as in peripheral $\mathrm{B}$ cells by specific antibodies would be beneficial for patients with $\mathrm{CHC}$ to achieve a complete viral clearance. Finally, although a positive association between HCV infection and B-NHL occurrence is still being debated [108-111], it is worthwhile to investigate the possible mechanisms by which B-cell lymphoproliferative disorders, which may evolve into B-NHL, are induced in patients with CHC.

\section{Acknowledgments}

The authors thank Dr. Miho Suzuki and Dr. Kenji Ikebuchi for providing us with blood samples. This work was supported by Grants-in-Aid from the Ministry of Health, Labour and Welfare, Japan.

\section{References}

[1] T. Suzuki, K. Ishii, H. Aizaki, and T. Wakita, "Hepatitis C viral life cycle," Advanced Drug Delivery Reviews, vol. 59, no. 12, pp. 1200-1212, 2007.

[2] G. M. Lauer and B. D. Walker, "Hepatitis C virus infection," New England Journal of Medicine, vol. 345, no. 1, pp. 41-52, 2001.

[3] N. H. Afdhal, "The natural history of hepatitis C," Seminars in Liver Disease, vol. 24, supplement 2, pp. 3-8, 2004.

[4] V. Agnello, R. T. Chung, and L. M. Kaplan, "A role for hepatitis C virus infection in type II cryoglobulinemia," New England Journal of Medicine, vol. 327, no. 21, pp. 1490-1495, 1992.

[5] E. Zuckerman, T. Zuckerman, A. M. Levine et al., "Hepatitis $\mathrm{C}$ virus infection in patients with B-cell non-Hodgkin lymphoma," Annals of Internal Medicine, vol. 127, no. 6, pp. 423428, 1997.

[6] S. de Sanjose, Y. Benavente, C. M. Vajdic et al., "Hepatitis C and non-Hodgkin lymphoma among 4784 cases and 6269 controls from the international lymphoma epidemiology consortium," Clinical Gastroenterology and Hepatology, vol. 6, no. 4, pp. 451-458, 2008.

[7] N. C. Turner, G. Dusheiko, and A. Jones, "Hepatitis C and Bcell lymphoma," Annals of Oncology, vol. 14, no. 9, pp. 13411345, 2003.

[8] C. Mazzaro, F. Franzin, P. Tulissi et al., "Regression of monoclonal B-cell expansion in patients affected by mixed cryoglobulinemia responsive to $\alpha$-interferon therapy," Cancer, vol. 77, no. 12, pp. 2604-2613, 1996.

[9] V. Agnello, C. Mecucci, M. Casato et al., "Regression of splenic lymphoma after treatment of hepatitis $\mathrm{C}$ virus infection," New England Journal of Medicine, vol. 347, no. 26, pp. 2168-2170, 2002.

[10] O. Hermine, F. Lefrère, J. P. Bronowicki et al., "Regression of splenic lymphoma with villous lymphocytes after treatment of hepatitis C virus infection," New England Journal of Medicine, vol. 347, no. 2, pp. 89-94, 2002.

[11] M. Houghton, A. Weiner, J. Han, G. Kuo, and Q. L. Choo, "Molecular biology of the hepatitis $\mathrm{C}$ viruses: implications for diagnosis, development and control of viral disease," Hepatology, vol. 14, no. 2, pp. 381-388, 1991.

[12] J. H. Han, V. Shyamala, K. H. Richman et al., "Characterization of the terminal regions of hepatitis C viral RNA: identification of conserved sequences in the 5' untranslated region and poly(A) tails at the 3' end," Proceedings of the National Academy of Sciences of the United States of America, vol. 88, no. 5, pp. 1711-1715, 1991.

[13] A. L. Zignego, D. Macchia, M. Monti et al., "Infection of peripheral mononuclear blood cells by hepatitis C virus," Journal of Hepatology, vol. 15, no. 3, pp. 382-386, 1992.

[14] C. Ferri, M. Monti, L. La Civita et al., "Infection of peripheral blood mononuclear cells by hepatitis $\mathrm{C}$ virus in mixed cryoglobulinemia," Blood, vol. 82, no. 12, pp. 3701-3704, 1993.

[15] H. M. Muller, E. Pfaff, T. Goeser, B. Kallinowski, C. Solbach, and L. Theilmann, "Peripheral blood leukocytes serve as a possible extrahepatic site for hepatitis C virus replication," Journal of General Virology, vol. 74, no. 4, pp. 669-676, 1993.

[16] J. Moldvay, P. Deny, S. Pol, C. Brechot, and E. Lamas, "Detection of hepatitis C virus RNA in peripheral blood mononuclear cells of infected patients by in situ hybridization," Blood, vol. 83, no. 1, pp. 269-273, 1994.

[17] L. Muratori, D. Gibellini, M. Lenzi et al., "Quantification of hepatitis $\mathrm{C}$ virus-infected peripheral blood mononuclear cells by in situ reverse transcriptase-polymerase chain reaction," Blood, vol. 88, no. 7, pp. 2768-2774, 1996.

[18] G. Morsica, G. Tambussi, G. Sitia et al., "Replication of hepatitis C virus in B lymphocytes $\left(\mathrm{CD} 19^{+}\right)$," Blood, vol. 94, no. 3, pp. 1138-1139, 1999.

[19] P. Pileri, Y. Uematsu, S. Campagnoli et al., "Binding of hepatitis C virus to CD81," Science, vol. 282, no. 5390, pp. 938-941, 1998.

[20] G. Z. Gong, L. Y. Lai, Y. F. Jiang, Y. He, and X. S. Su, "HCV replication in PBMC and its influence on interferon therapy," World Journal of Gastroenterology, vol. 9, no. 2, pp. 291-294, 2003.

[21] D. Sansonno, A. R. Iacobelli, V. Cornacchiulo, G. Iodice, and F. Dammacco, "Detection of hepatitis $\mathrm{C}$ virus (HCV)proteins by immunofluorescence and HCV RNA genomic sequences by non-isotopic in situ hybridization in bone marrow and peripheral blood mononuclear cells of chronically HCVinfected patients," Clinical and Experimental Immunology, vol. 103, no. 3, pp. 414-421, 1996. 
[22] I. Castillo, M. Pardo, J. Bartolomé et al., "Occult hepatitis C virus infection in patients in whom the etiology of persistently abnormal results of liver-function tests is unknown," Journal of Infectious Diseases, vol. 189, no. 1, pp. 7-14, 2004.

[23] I. Castillo, E. Rodríguez-Iñigo, J. Bartolomé et al., "Hepatitis $\mathrm{C}$ virus replicates in peripheral blood mononuclear cells of patients with occult hepatitis C virus infection," Gut, vol. 54, no. 5, pp. 682-685, 2005.

[24] D. Januszkiewicz-Lewandowska, J. Wysocki, M. Pernak et al., "Presence of hepatitis $\mathrm{C}$ virus (HCV)-RNA in peripheral blood mononuclear cells in HCV serum negative patients during interferon and ribavirin therapy," Japanese Journal of Infectious Diseases, vol. 60, no. 1, pp. 29-32, 2007.

[25] C. Caussin-Schwemling, C. Schmitt, and F. Stoll-Keller, "Study of the infection of human blood derived monocyte/ macrophages with hepatitis C virus in vitro," Journal of Medical Virology, vol. 65, no. 1, pp. 14-22, 2001.

[26] J. Greeve, A. Philipsen, K. Krause et al., "Expression of activation-induced cytidine deaminase in human B-cell non-Hodgkin lymphomas," Blood, vol. 101, no. 9, pp. 3574-3580, 2003.

[27] M. C. Navas, A. Fuchs, E. Schvoerer, A. Bohbot, A. M. Aubertin, and F. Stoll-Keller, "Dendritic cell susceptibility to hepatitis C virus genotype 1 infection," Journal of Medical Virology, vol. 67, no. 2, pp. 152-161, 2002.

[28] Y. Kondo, Y. Ueno, E. Kakazu et al., "Lymphotropic HCV strain can infect human primary naïve $\mathrm{CD} 4^{+}$cells and affect their proliferation and IFN- $\gamma$ secretion activity," Journal of Gastroenterology, vol. 46, no. 2, pp. 232-241, 2010.

[29] J. T. Blackard, N. Kemmer, and K. E. Sherman, "Extrahepatic replication of HCV: insights into clinical manifestations and biological consequences," Hepatology, vol. 44, no. 1, pp. 15-22, 2006.

[30] D. Ducoulombier, A. M. Roque-Afonso, G. Di Liberto et al., "Frequent compartmentalization of hepatitis $\mathrm{C}$ virus variants in circulating B cells and monocytes," Hepatology, vol. 39, no. 3, pp. 817-825, 2004.

[31] H. M. Müller, B. Kallinowski, C. Solbach, L. Theilmann, T. Goeser, and E. Pfaff, "B-lymphocytes are predominantly involved in viral propagation of hepatitis C virus (HCV)," Archives of Virology. Supplementum, vol. 9, pp. 307-316, 1994.

[32] M. Ito, K. Murakami, T. Suzuki et al., "Enhanced expression of lymphomagenesis-related genes in peripheral blood B cells of chronic hepatitis C patients," Clinical Immunology, vol. 135, no. 3, pp. 459-465, 2010.

[33] M. Inokuchi, T. Ito, M. Uchikoshi et al., "Infection of B cells with hepatitis $\mathrm{C}$ virus for the development of lymphoproliferative disorders in patients with chronic hepatitis C," Journal of Medical Virology, vol. 81, no. 4, pp. 619-627, 2009.

[34] M. Zuker, "On findings all suboptimal foldings of an RNA molecule," Science, vol. 244, no. 4900, pp. 48-52, 1989.

[35] T. Durand, G. Di Liberto, H. Colman et al., "Occult infection of peripheral B cells by hepatitis $\mathrm{C}$ variants which have low translational efficiency in cultured hepatocytes," Gut, vol. 59, no. 7, pp. 934-942, 2010.

[36] S. Akira, S. Uematsu, and O. Takeuchi, "Pathogen recognition and innate immunity," Cell, vol. 124, no. 4, pp. 783-801, 2006.

[37] M. Yoneyama, M. Kikuchi, T. Natsukawa et al., "The RNA helicase RIG-I has an essential function in double-stranded RNA-induced innate antiviral responses," Nature Immuno$\log y$, vol. 5, no. 7, pp. 730-737, 2004.

[38] D. B. Stetson and R. Medzhitov, "Type I interferons in host defense," Immunity, vol. 25, no. 3, pp. 373-381, 2006.
[39] J. Vilcek, "Fifty years of interferon research: aiming at a moving target," Immunity, vol. 25, no. 3, pp. 343-348, 2006.

[40] K. A. Fitzgerald, S. M. McWhirter, K. L. Faia et al., "IKKe and TBK1 are essential components of the IRF3 signaling pathway," Nature Immunology, vol. 4, no. 5, pp. 491-496, 2003.

[41] K. Yang, H. Shi, R. Qi et al., "Hsp90 regulates activation of interferon regulatory factor 3 and TBK-1 stabilization in Sendai virus-infected cells," Molecular Biology of the Cell, vol. 17, no. 3, pp. 1461-1471, 2006.

[42] M. Schröder, M. Baran, and A. G. Bowie, "Viral targeting of DEAD box protein 3 reveals its role in TBK1/IKKemediated IRF activation," EMBO Journal, vol. 27, no. 15, pp. 2147-2157, 2008.

[43] J. Huang, T. Liu, L. G. Xu, D. Chen, Z. Zhai, and H. B. Shu, "SIKE is an IKK $\varepsilon /$ TBK1-associated suppressor of TLR3- and virus-triggered IRF-3 activation pathways," EMBO Journal, vol. 24, no. 23, pp. 4018-4028, 2005.

[44] K. Agematsu, S. Hokibara, H. Nagumo, and A. Komiyama, "CD27: a memory B-cell marker," Immunology Today, vol. 21, no. 5, pp. 204-206, 2000.

[45] T. Mizuochi, M. Ito, K. Saito et al., "Possible recruitment of peripheral blood $\mathrm{CXCR}^{+} \mathrm{CD} 27^{+} \mathrm{CD} 19^{+} \mathrm{B}$ cells to the liver of chronic hepatitis C patients," Journal of Interferon and Cytokine Research, vol. 30, no. 4, pp. 243-252, 2010.

[46] S. Pal, D. G. Sullivan, S. Kim et al., "Productive replication of hepatitis $\mathrm{C}$ virus in perihepatic lymph nodes in vivo: implications of HCV lymphotropism," Gastroenterology, vol. 130, no. 4, pp. 1107-1116, 2006.

[47] T. N. Pham and T. I. Michalak, "Occult persistence and lymphotropism of hepatitis C virus infection," World Journal of Gastroenterology, vol. 14, no. 18, pp. 2789-2793, 2008.

[48] T. N. Pham, D. King, S. A. MacParland et al., "Hepatitis C virus replicates in the same immune cell subsets in chronic hepatitis C and occult infection," Gastroenterology, vol. 134, no. 3, pp. 812-822, 2008.

[49] B. Rehermann, "Hepatitis $C$ virus versus innate and adaptive immune responses: a tale of coevolution and coexistence," Journal of Clinical Investigation, vol. 119, no. 7, pp. 17451754, 2009.

[50] S. Merani, D. Petrovic, I. James et al., "Effect of immune pressure on hepatitis $\mathrm{C}$ virus evolution: insights from a single-source outbreak," Hepatology, vol. 53, no. 2, pp. 396-405, 2011.

[51] D. R. Taylor, S. T. Shi, P. R. Romano, G. N. Barber, and M. M. Lai, "Inhibition of the interferon-inducible protein kinase PKR by HCV E2 protein," Science, vol. 285, no. 5424, pp. 107-110, 1999.

[52] E. Foy, K. Li, C. Wang et al., "Regulation of interferon regulatory factor-3 by the hepatitis C virus serine protease," Science, vol. 300, no. 5622, pp. 1145-1148, 2003.

[53] E. Foy, K. Li, R. Sumpter Jr. et al., "Control of antiviral defenses through hepatitis $\mathrm{C}$ virus disruption of retinoic acid-inducible gene-I signaling," Proceedings of the National Academy of Sciences of the United States of America, vol. 102, no. 8, pp. 2986-2991, 2005.

[54] S. J. Polyak, K. S. Khabar, D. M. Paschal et al., "Hepatitis $\mathrm{C}$ virus nonstructural $5 \mathrm{~A}$ protein induces interleukin-8, leading to partial inhibition of the interferon-induced antiviral response," Journal of Virology, vol. 75, no. 13, pp. 6095-6106, 2001.

[55] M. J. Gale Jr., M. J. Korth, N. M. Tang et al., "Evidence that hepatitis $\mathrm{C}$ virus resistance to interferon is mediated through repression of the PKR protein kinase by the nonstructural 5A protein," Virology, vol. 230, no. 2, pp. 217-227, 1997. 
[56] M. H. Heim, D. Moradpour, and H. E. Blum, "Expression of hepatitis $\mathrm{C}$ virus proteins inhibits signal transduction through the Jak-STAT pathway," Journal of Virology, vol. 73, no. 10, pp. 8469-8475, 1999.

[57] W. Lin, S. S. Kim, E. Yeung et al., "Hepatitis C virus core protein blocks interferon signaling by interaction with the STAT1 SH2 domain," Journal of Virology, vol. 80, no. 18, pp. 9226-9235, 2006.

[58] R. Misiani, P. Bellavita, D. Fenili et al., "Hepatitis C virus infection in patients with essential mixed cryoglobulinemia," Annals of Internal Medicine, vol. 117, no. 7, pp. 573-577, 1992.

[59] C. Ferri, L. La Civita, G. Longombardo, F. Greco, and S. Bombardieri, "Hepatitis C virus and mixed cryoglobulinaemia," European Journal of Clinical Investigation, vol. 23, no. 7, pp. 399-405, 1993.

[60] C. Ferri, L. La Civita, A. L. Zignego, and G. Pasero, "Viruses and cancers: possible role of hepatitis C virus," European Journal of Clinical Investigation, vol. 27, no. 9, pp. 711-718, 1997.

[61] L. Sansonno, F. A. Tucci, S. Sansonno, G. Lauletta, L. Troiani, and D. Sansonno, "B cells and HCV: an infection model of autoimmunity," Autoimmunity Reviews, vol. 9, no. 2, pp. 93-94, 2009.

[62] C. Mazzaro, V. Zagonel, S. Monfardini et al., "Hepatitis C virus and non-Hodgkin's lymphomas," British Journal of Haematology, vol. 94, no. 3, pp. 544-550, 1996.

[63] J. P. Gisbert, L. García-Buey, J. M. Pajares, and R. MorenoOtero, "Prevalence of hepatitis C virus infection in B-cell non-Hodgkin's lymphoma: systematic review and metaanalysis," Gastroenterology, vol. 125, no. 6, pp. 1723-1732, 2003.

[64] K. Matsuo, A. Kusano, A. Sugumar, S. Nakamura, K. Tajima, and N. E. Mueller, "Effect of hepatitis $\mathrm{C}$ virus infection on the risk of non-Hodgkin's lymphoma: a meta-analysis of epidemiological studies," Cancer Science, vol. 95, no. 9, pp. 745-752, 2004.

[65] E. Negri, D. Little, M. Boiocchi, C. La Vecchia, and S. Franceschi, "B-cell non-Hodgkin's lymphoma and hepatitis C virus infection: a systematic review," International Journal of Cancer, vol. 111, no. 1, pp. 1-8, 2004.

[66] A. Nieters, B. Kallinowski, P. Brennan et al., "Hepatitis C and risk of lymphoma: results of the European multicenter case-control study EPILYMPH," Gastroenterology, vol. 131, no. 6, pp. 1879-1886, 2006.

[67] A. Durandy, "Activation-induced cytidine deaminase: a dual role in class-switch recombination and somatic hypermutation," European Journal of Immunology, vol. 33, no. 8, pp. 2069-2073, 2003.

[68] M. Muramatsu, K. Kinoshita, S. Fagarasan, S. Yamada, Y. Shinkai, and T. Honjo, "Class switch recombination and hypermutation require activation-induced cytidine deaminase (AID), a potential RNA editing enzyme," Cell, vol. 102, no. 5, pp. 553-563, 2000.

[69] I. Okazaki, K. Yoshikawa, K. Kinoshita, M. Muramatsu, H. Nagaoka, and T. Honjo, "Activation-induced cytidine deaminase links class switch recombination and somatic hypermutation," Annals of the New York Academy of Sciences, vol. 987, pp. 1-8, 2003.

[70] R. Küppers and R. Dalla-Favera, "Mechanisms of chromosomal translocations in B cell lymphomas," Oncogene, vol. 20, no. 40, pp. 5580-5594, 2001.

[71] L. Pasqualucci, P. Neumeister, T. Goossens et al., "Hypermutation of multiple proto-oncogenes in B-cell diffuse large-cell lymphomas," Nature, vol. 412, no. 6844, pp. 341-346, 2001.
[72] M. Okano, "Haematological associations of Epstein-Barr virus infection," Bailliere's Best Practice and Research in Clinical Haematology, vol. 13, no. 2, pp. 199-214, 2000.

[73] M. Libra, D. Capello, A. Gloghini et al., "Analysis of aberrant somatic hypermutation (SHM) in non-Hodgkin's lymphomas of patients with chronic HCV infection," Journal of Pathology, vol. 206, no. 1, pp. 87-91, 2005.

[74] V. M Sung, S. Shimodaira, A. L. Doughty et al., "Establishment of B-cell lymphoma cell lines persistently infected with hepatitis $C$ virus in vivo and in vitro: the apoptotic effects of virus infection," Journal of Virology, vol. 77, no. 3, pp. 2134-2146, 2003.

[75] K. Machida, K. T. Cheng, V. M. Sung et al., "Hepatitis C virus induces a mutator phenotype: enhanced mutations of immunoglobulin and protooncogenes," Proceedings of the National Academy of Sciences of the United States of America, vol. 101, no. 12, pp. 4262-4267, 2004.

[76] L. Pasqualucci, R. Guglielmino, J. Houldsworth et al., "Expression of the AID protein in normal and neoplastic B cells," Blood, vol. 104, no. 10, pp. 3318-3325, 2004.

[77] L. A. Smit, R. J. Bende, J. Aten, J. E. Guikema, W. M. Aarts, and C. J. van Noesel, "Expression of activation-induced cytidine deaminase is confined to B-cell non-Hodgkin's lymphomas of germinal-center phenotype," Cancer Research, vol. 63, no. 14, pp. 3894-3898, 2003.

[78] L. Pasqualucci, G. Bhagat, M. Jankovic et al., "AID is required for germinal center-derived lymphomagenesis," Nature Genetics, vol. 40, no. 1, pp. 108-112, 2008.

[79] C. Schöllkopf, K. E. Smedby, H. Hjalgrim et al., "Hepatitis $\mathrm{C}$ infection and risk of malignant lymphoma," International Journal of Cancer, vol. 122, no. 8, pp. 1885-1890, 2008.

[80] I. M. Okazaki, H. Hiai, N. Kakazu et al., "Constitutive expression of AID leads to tumorigenesis," Journal of Experimental Medicine, vol. 197, no. 9, pp. 1173-1181, 2003.

[81] I. M. Okazaki, A. Kotani, and T. Honjo, "Role of AID in tumorigenesis," Advances in Immunology, vol. 94, pp. 245-273, 2007.

[82] T. Chiba and H. Marusawa, "A novel mechanism for inflammation-associated carcinogenesis; an important role of activation-induced cytidine deaminase (AID) in mutation induction," Journal of Molecular Medicine, vol. 87, pp. 1023-1027, 2009.

[83] Y. Komeno, J. Kitaura, N. Watanabe-Okochi et al., "AIDinduced T-lymphoma or B-leukemia/lymphoma in a mouse BMT model," Leukemia, vol. 24, no. 5, pp. 1018-1024, 2010.

[84] C. Ishikawa, S. Nakachi, M. Senba, M. Sugai, and N. Mori, "Activation of AID by human T-cell leukemia virus Tax oncoprotein and the possible role of its constitutive expression in ATL genesis," Carcinogenesis, vol. 32, no. 1, pp. 110-119, 2011.

[85] J. K. Oem, C. Jackel-Cram, Y. P. Li et al., "Hepatitis C virus non-structural protein-2 activates CXCL-8 transcription through NF- $\kappa \mathrm{B}$," Archives of Virology, vol. 153, no. 2, pp. 293-301, 2008.

[86] Y. Endo, H. Marusawa, K. Kinoshita et al., "Expression of activation-induced cytidine deaminase in human hepatocytes via NF- $\kappa \mathrm{B}$ signaling," Oncogene, vol. 26 , no. 38 , pp. 5587-5595, 2007.

[87] S. Nakamura, Y. Yatabe, and M. Seto, "Cyclin D1 overexpression in malignant lymphomas," Pathology International, vol. 47, no. 7, pp. 421-429, 1997.

[88] M. Fu, C. Wang, Z. Li, T. Sakamaki, and R. G. Pestell, "Minireview: Cyclin D1: normal and abnormal functions," Endocrinology, vol. 145, no. 12, pp. 5439-5447, 2004. 
[89] S. Wessendorf, C. Schwaenen, H. Kohlhammer et al., "Hidden gene amplifications in aggressive B-cell non-Hodgkin lymphomas detected by microarray-based comparative genomic hybridization," Oncogene, vol. 22, no. 9, pp. 14251429, 2003.

[90] R. C. Aguiar, Y. Yakushijin, S. Kharbanda, R. Salgia, J. A. Fletcher, and M. A. Shipp, "BAL is a novel risk-related gene in diffuse large B-cell lymphomas that enhances cellular migration," Blood, vol. 96, no. 13, pp. 4328-4334, 2000.

[91] M. Hamada, Y. Yakushijin, M. Ohtsuka, M. Kakimoto, M. Yasukawa, and S. Fujita, "Aurora2/BTAK/STK15 is involved in cell cycle checkpoint and cell survival of aggressive non-Hodgkin's lymphoma," British Journal of Haematology, vol. 121, no. 3, pp. 439-447, 2003.

[92] K. K. Hoyer, M. Pang, D. Gui et al., "An anti-apoptotic role for galectin-3 in diffuse large B-cell lymphomas," American Journal of Pathology, vol. 164, no. 3, pp. 893-902, 2004.

[93] A. W. Opipari Jr., M. S. Boguski, and V. M. Dixit, “The A20 cDNA induced by tumor necrosis factor $\alpha$ encodes a novel type of zinc finger protein," Journal of Biological Chemistry, vol. 265, no. 25, pp. 14705-14708, 1990.

[94] H. Y. Song, M. Rothe, and D. V. Goeddel, "The tumor necrosis factor-inducible zinc finger protein A20 interacts with TRAF1/TRAF2 and inhibits NF- $\kappa$ B activation," Proceedings of the National Academy of Sciences of the United States of America, vol. 93, no. 13, pp. 6721-6725, 1996.

[95] E. G. Lee, D. L. Boone, S. Chai et al., "Failure to regulate TNFinduced NF- $\kappa \mathrm{B}$ and cell death responses in A20-deficient mice," Science, vol. 289, no. 5488, pp. 2350-2354, 2000.

[96] K. Heyninck and R. Beyaert, "A20 inhibits NF- $\kappa$ B activation by dual ubiquitin-editing functions," Trends in Biochemical Sciences, vol. 30, no. 1, pp. 1-4, 2005.

[97] B. A. Malynn and A. Ma, "A20 takes on tumors: tumor suppression by an ubiquitin-editing enzyme," Journal of Experimental Medicine, vol. 206, no. 5, pp. 977-980, 2009.

[98] S. G. Hymowitz and I. E. Wertz, "A20: from ubiquitin editing to tumour suppression," Nature Reviews Cancer, vol. 10, no. 5, pp. 332-341, 2010.

[99] K. Honma, S. Tsuzuki, M. Nakagawa et al., "TNFAIP3 is the target gene of chromosome band 6q23.3-q24.1 loss in ocular adnexal marginal zone B cell lymphoma," Genes Chromosomes and Cancer, vol. 47, no. 1, pp. 1-7, 2008.

[100] K. Honma, S. Tsuzuki, M. Nakagawa et al., "TNFAIP3/A20 functions as a novel tumor suppressor gene in several subtypes of non-Hodgkin lymphomas," Blood, vol. 114, no. 12, pp. 2467-2475, 2009.

[101] M. Kato, M. Sanada, I. Kato et al., "Frequent inactivation of A20 in B-cell lymphomas," Nature, vol. 459, no. 7247, pp. 712-716, 2009.

[102] M. Compagno, W. K. Lim, A. Grunn et al., "Mutations of multiple genes cause deregulation of NF- $\kappa \mathrm{B}$ in diffuse large B-cell lymphoma," Nature, vol. 459, no. 7247, pp. 717-721, 2009.

[103] K. Parvatiyar and E. W. Harhaj, "Regulation of inflammatory and antiviral signaling by A20," Microbes and Infection, vol. 13, no. 3, pp. 209-215, 2011.

[104] K. Parvatiyar, G. N. Barber, and E. W. Harhaj, “TAX1BP1 and A20 inhibit antiviral signaling by targeting TBK1-IKKi kinases," Journal of Biological Chemistry, vol. 285, no. 20, pp. 14999-15009, 2010.

[105] R. M. Tavares, E. E. Turer, C. L. Liu et al., "The ubiquitin modifying enzyme A20 restricts B cell survival and prevents autoimmunity," Immunity, vol. 33, no. 2, pp. 181-191, 2010.
[106] L. Verstrepen, K. Verhelst, G. van Loo, I. Carpentier, S. C. Ley, and R. Beyaert, "Expression, biological activities and mechanisms of action of A20 (TNFAIP3)," Biochemical Pharmacology, vol. 80, no. 12, pp. 2009-2020, 2010.

[107] H. Nguyen, S. Sankaran, and S. Dandekar, "Hepatitis C virus core protein induces expression of genes regulating immune evasion and anti-apoptosis in hepatocytes," Virology, vol. 354, no. 1, pp. 58-68, 2006.

[108] G. Germanidis, C. Haioun, J. Pourquier et al., "Hepatitis C virus infection in patients with overt B-cell non-Hodgkin's lymphoma in a French center," Blood, vol. 93, no. 5, pp. 1778-1779, 1999.

[109] J. D. Collier, B. Zanke, M. Moore et al., "No association between hepatitis C and B-cell lymphoma," Hepatology, vol. 29, no. 4, pp. 1259-1261, 1999.

[110] C. Udomsakdi-Auewarakul, P. Auewarakul, S. Sukpanichnant, and W. Muangsup, "Hepatitis C virus infection in patients with non-Hodgkin lymphoma in Thailand," Blood, vol. 95, no. 11, pp. 3640-3641, 2000.

[111] L. Dal Maso and S. Franceschi, "Hepatitis C virus and risk of lymphoma and other lymphoid neoplasms: a meta-analysis of epidemiologic studies," Cancer Epidemiology Biomarkers and Prevention, vol. 15, no. 11, pp. 2078-2085, 2006. 


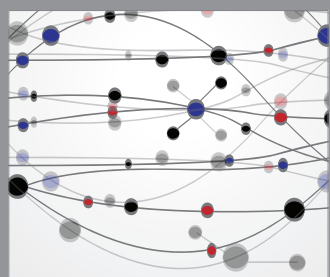

The Scientific World Journal
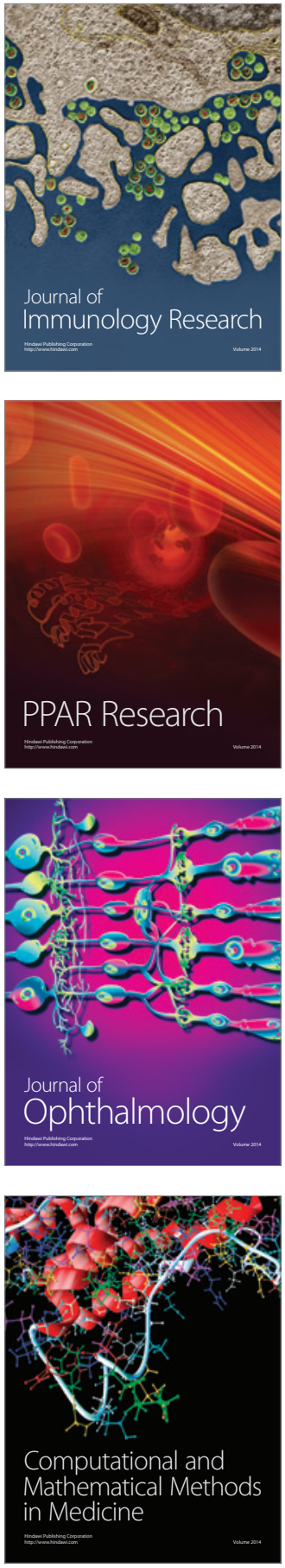

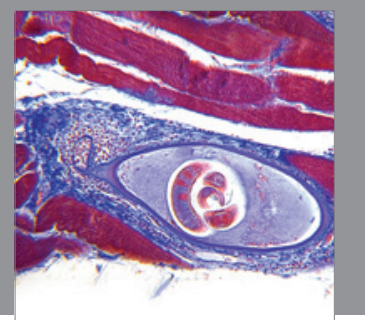

Gastroenterology

Research and Practice
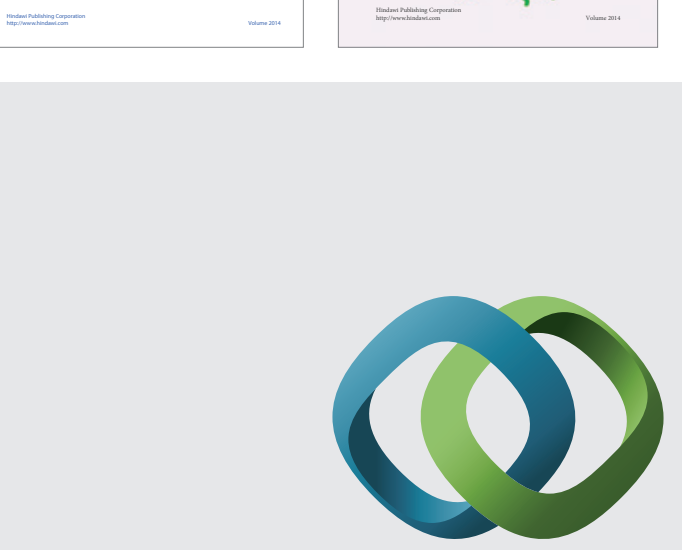

\section{Hindawi}

Submit your manuscripts at

http://www.hindawi.com
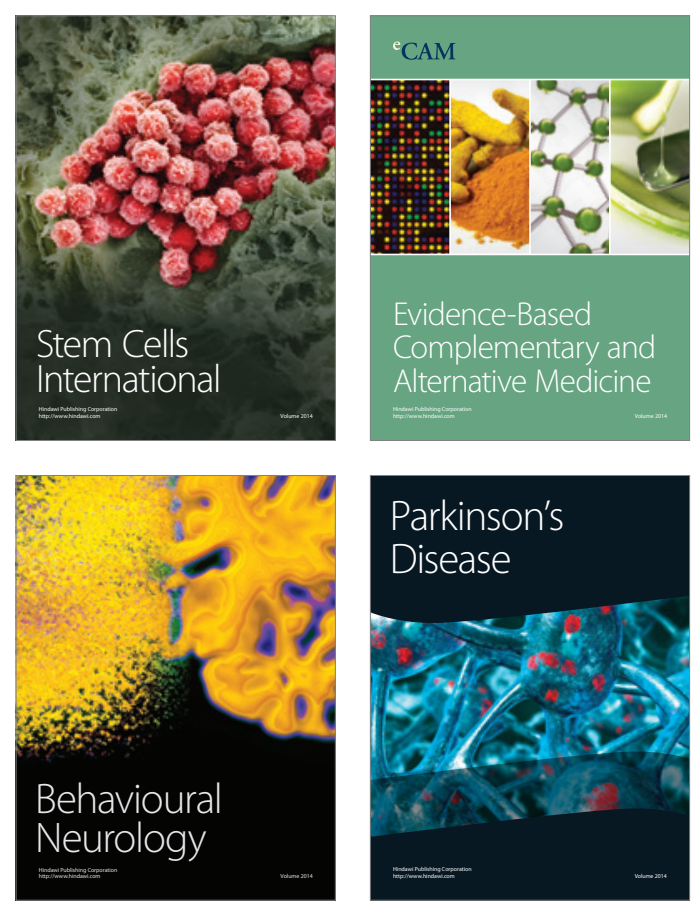

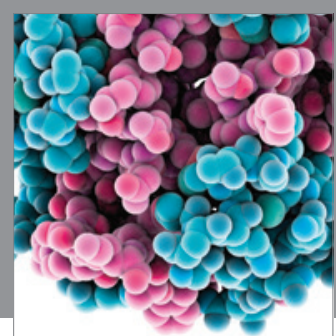

Journal of
Diabetes Research

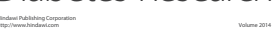

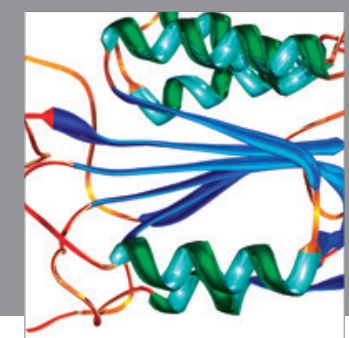

Disease Markers
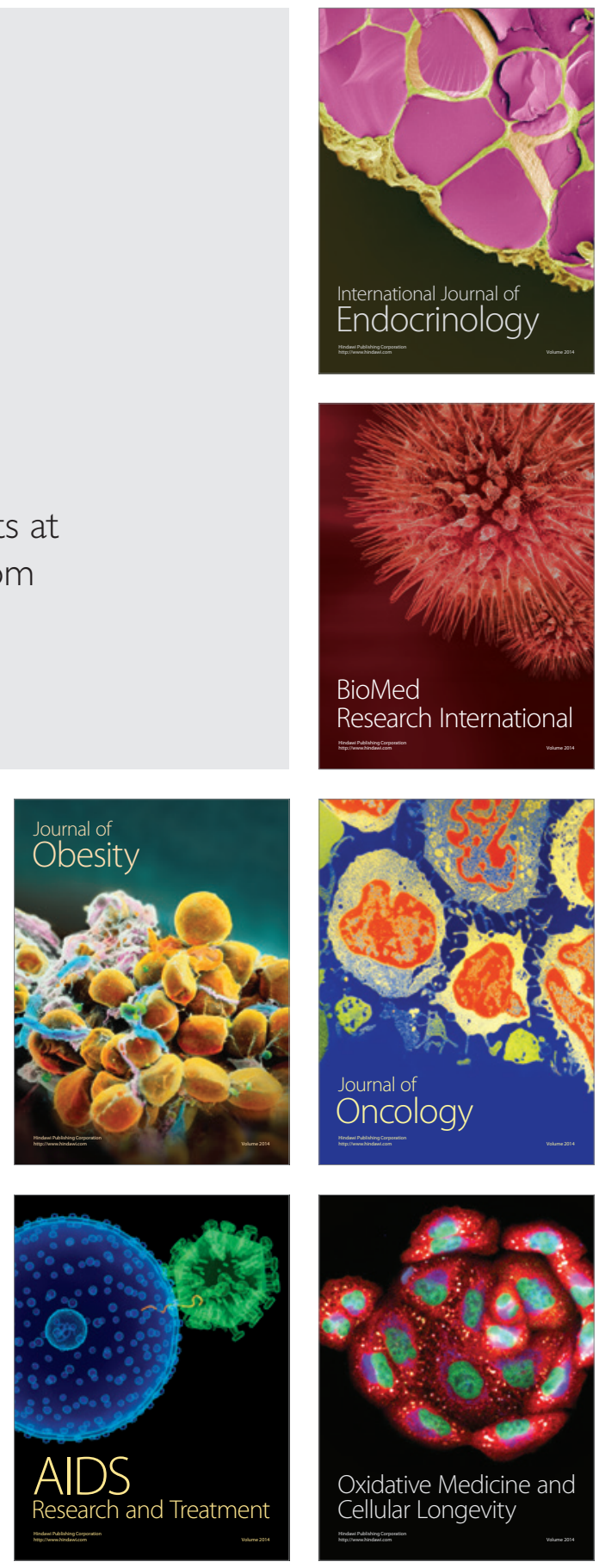